\title{
Operation of a Low Voltage Distribution Grid in Cyprus and the Impact of Photovoltaics and Electric Vehicles
}

\author{
Andreas Kotsonias, Lenos Hadjidemetriou, Elias Kyriakides \\ KIOS Research and Innovation Center of Excellence and \\ Department of Electrical and Computer Engineering \\ University of Cyprus \\ Nicosia, Cyprus \\ Email: \{kotsonias.andreas, hadjidemetriou.lenos, \\ elias\}@ucy.ac.cy
}

\author{
Yiannakis Ioannou \\ Electricity Authority of Cyprus \\ Nicosia, Cyprus \\ Email: \{Yioannou@eac.com.cy\}
}

\begin{abstract}
The operation of a typical 4-wire, radial, Low Voltage Distribution Grid (LVDG) in the Cyprus power system, where the neutral conductor is grounded only at the $\mathrm{MV} / \mathrm{LV}$ transformer, is investigated under different scenarios. These include seasonal loading profiles and different penetration levels of photovoltaics (PVs) and electric vehicles (EVs). The analysis is focused on the impact of PVs and EVs on the voltage profile of the LVDG, the loading conditions of the distribution lines/cables and on the system losses. The results indicate that even with a moderate number of PVs, the admissible voltage limits can be exceeded due to the significant voltage drop across the neutral conductor. Moreover, the distribution lines/cables near the transformer can be overloaded if the charging process of the electric vehicles is not coordinated and is left freely to end users.
\end{abstract}

Index Terms-Electric vehicles, low voltage distribution grid, overloading conditions, photovoltaics, voltage profile.

\section{INTRODUCTION}

Environmental concerns, the rising cost of electricity and the ambition of zero dependency on fossil fuels are driving the growth of Distributed Energy Resources (DERs) in the LVDG. In Europe, due to the targets set by the EU for the reduction of $\mathrm{CO}_{2}$ emissions, many governments have been creating incentives in order to encourage the consumers to invest in ecofriendly technologies such as residential rooftop PV systems and EVs [1]-[2]. As a result, over the past few years the penetration level of DERs, especially the number of PVs, inside the LVDG has been increasing rapidly. According to [3], the global installed capacity of residential PV systems from 2010 to 2016 has been quadrupled and it is expected that by 2021 there will be a $60 \%$ further increase in its installed capacity. Such a massive penetration of distributed generation into an aging infrastructure that has been designed for unidirectional power flow, with limited upgrades over the years, will impose new challenges and obstacles to the Distribution System Operators (DSOs) for ensuring the secure and reliable operation of distribution grids [4]. So far, it was assumed that if the voltage is regulated at a higher level, then the voltage profile in the LVDG would satisfy the operational standards. However, with the introduction of these new technologies this is not a safe assumption anymore and a better understanding of the behavior of the LVDG is required. Specifically, the detrimental impacts of DERs (including PV systems and EV charging facilities) and their consequences in the operation of the LVDG must be studied so that the DSOs can accommodate their increasing penetration levels while maintaining a high quality of power supplied. In [5], monitoring equipment was installed at selected low voltage substations and feeders in the UK in order to gain a better understanding of their voltage characteristics. The results indicate that the overvoltage problem induced by the PVs is more serious and more common rather than the undervoltage problem. Similar issues appear also in a German LVDG with high penetration of PVs [6] where the PVs create instances of high reverse power flow. During these instances, the voltage magnitudes exceeded the upper voltage limit of $253 \mathrm{~V}$ and the neutral conductor was overloaded with 80 A of current. A study in [7] focusing on a Swedish urban area has revealed potential overloading issues of the installed cables under high penetration levels of PVs. Similarly, in [8] simulation studies were conducted in a residential LVDG in Western Australia in which the results have also shown potential overvoltage issues under high PV penetration.

This paper investigates the operation of a typical sub-urban LVDG in the power system of Cyprus, in which the neutral conductor is grounded only at the $\mathrm{MV} / \mathrm{LV} \mathrm{D}-\mathrm{Y}_{\mathrm{g}}$ transformer. The investigation scenarios include different seasonal loading conditions as well as different penetration levels for the PVs and the EVs. The analysis of the simulated results is focused on the voltage profile across the system, the loading of the distribution lines and the system losses. Additionally, a simple, low cost solution is suggested in order to reduce the voltage violations that may occur in the LVDG. The paper is organized as follows. In Section II the model and topology of the system is introduced, while in Section III the case studies are outlined and the results presented. Finally, the paper concludes in Section IV.
This work was partially supported by the European Regional Development Fund and the Republic of Cyprus through the Research and Innovation Foundation (Project: INTEGRATED/0916/0035). This work was also supported by the Electricity Authority of Cyprus (EAC) through the EU's strategic Horizon 2020 program for "Spreading Excellence and Widening Participation - Teaming." 


\section{SyStem Model}

The single line diagram of the considered LVDG is illustrated in Fig 1. This system represents a typical 4-wire LVDG in Cyprus which mainly serves single-phase and a small number of three-phase loads. In total there are 49 service points and 61 consumers (some service points have multiple meters and are supplying multiple consumers), of which 52 are domestic and 9 are commercial. Additionally, there are $3 \mathrm{PV}$ systems installed at nodes 7,17 and 42 (denoted with a green font number in Fig. 1) with rated power of $2.5 \mathrm{kWp}, 7.35 \mathrm{kWp}$ and $4.05 \mathrm{kWp}$ respectively. The main elements of this LVDG are described in this section, as well as the charging of EVs which is considered in the future operating scenarios.

\section{A. Distribution Lines/Cables}

Due to the highly unbalanced operation of LVDGs, the single-phase equivalent model is not suitable and thus, both series and mutual impedances of the conductors of a distribution line/cable need to be calculated. Moreover, due to the fact that the neutral conductor is only grounded at the $\mathrm{MV} / \mathrm{LV}$ transformer in this system, the application of the Kron's reduction method does not give an accurate picture and therefore the full $4 \times 4$ impedance matrix for each distribution line/cable is used [9]. Each element of the impedance matrix is calculated based on [9] and the conductor characteristics which are provided in Table I.

TABLE I

Distribution Line/CABLE CONDUCTOR CHARACTERISTICS

\begin{tabular}{cccc}
\hline \hline Distribution line/cable & GMR $(\mathrm{cm})$ & $\mathrm{R}_{\mathrm{ac}}(\Omega / \mathrm{km})$ & Capacity $(\mathrm{A})$ \\
\hline \hline $100 \mathrm{~mm}^{2} \mathrm{OHL}^{\mathrm{a}}$ & 0.4778 & 0.2702 & 271 \\
$50 \mathrm{~mm}^{2} \mathrm{OHL}$ & 0.3374 & 0.5419 & 181 \\
$22 \mathrm{~mm}^{2} \mathrm{OHL}$ & 0.2242 & 1.2271 & 155 \\
$16 \mathrm{~mm}^{2} \mathrm{OHL}$ & 0.1852 & 1.9102 & 155 \\
$185 / 90 \mathrm{~mm}^{2} \mathrm{UGC}$ & 0.6878 & 0.1432 & 320 \\
\hline \hline & & & b. Underground cable
\end{tabular}

\section{B. Consumers - Loads}

The load profiles have been constructed considering a dataset that consists of the recorded consumption pattern (through smart meters) of over 60 consumers in Cyprus for a whole calendar year. The dataset contains the half-hourly load demand records of consumers distributed all over Cyprus as provided by the Cyprus DSO (EAC). In Fig. 2, a typical

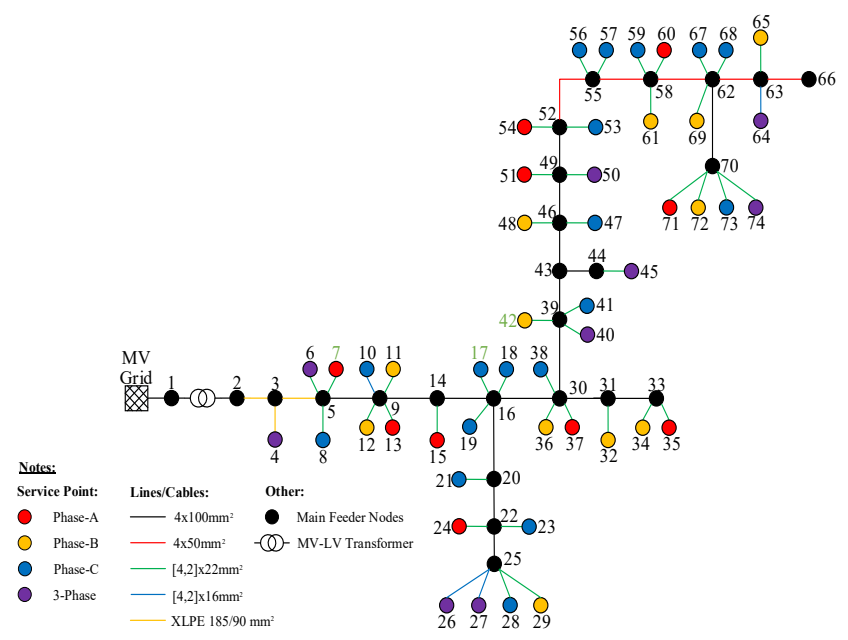

Figure 1. Single line diagram of the considered LVDG in Cyprus
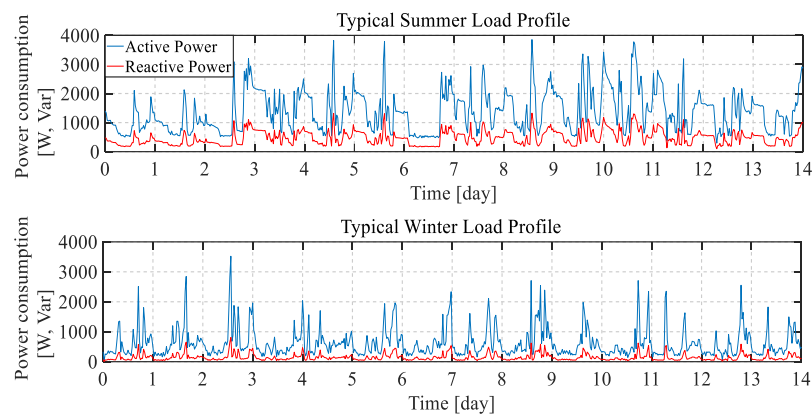

Figure 2. Typical summer/winter load profiles

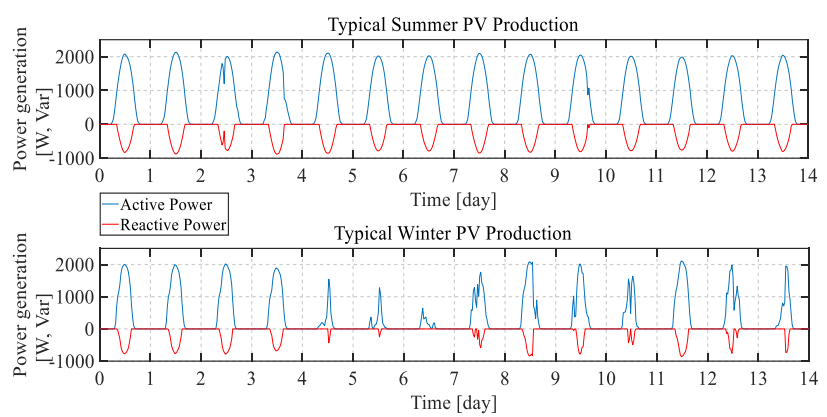

Figure 3. Typical summer/winter PV power generation

summer/winter load profile from the dataset is illustrated over a period of two weeks. The increase of load during the summer is mainly due to the use of cooling (AC) devices. It should be noted that a constant power load model is considered in this study for each consumer.

\section{PV Systems}

The dataset provided by the DSO (EAC) also contains the active power injection from PVs for a whole calendar year. The reactive power at each time instance is determined according to the EAC regulations for PV interconnection in LVDGs [10]. In Fig. 3 a typical summer/winter power generation profile from a single $2.5 \mathrm{kWp}$ PV system is illustrated.

\section{Electric Vehicles}

Although the number of fully electric vehicles is limited at the moment in Cyprus, it is expected that in the coming years a significant part of the transportation sector will be electrified. Therefore, in some of the simulation scenarios it is assumed that a number of consumers drive an EV and that they are equipped with a home charging equipment. For the construction of the charging profile of each EV the below assumptions are made:

- Battery capacity: $B_{c a p}=45 \mathrm{kWh}$

- Charging power: $P_{c h}=3.4 \mathrm{~kW}$ or $7 \mathrm{~kW}$ (the most common option for a home charger)

- Driving range at full charge: $200 \mathrm{~km}$

The procedure followed to construct the charging profiles of each EV is illustrated in Fig. 4. First, each EV is classified as either intercity or intracity. Then, based on this classification, the daily driving distance of each EV for the number of days simulated is obtained from a normal distribution. The mean and standard deviation for intercity traveling are chosen as $80 \mathrm{~km}$ and $10 \mathrm{~km}$ respectively, while for intracity traveling the mean and standard deviation are chosen as $10 \mathrm{~km}$ and $5 \mathrm{~km}$ 


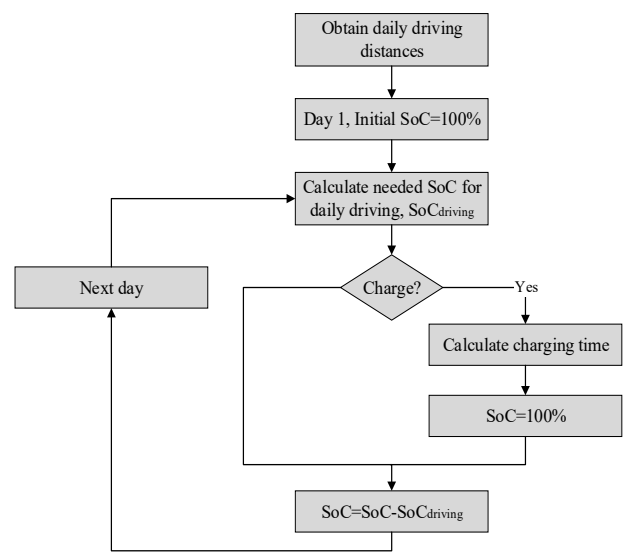

Figure 4. Constructing the charging profiles of the EVs

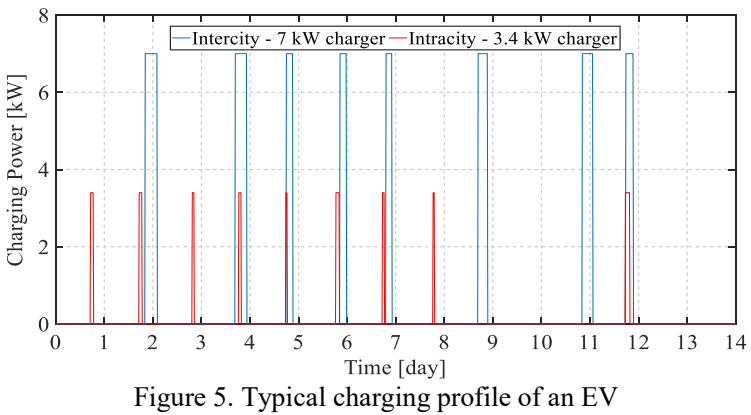

respectively (considering average intercity and intracity traveling distance in Cyprus). Additionally, each EV is assigned randomly to either a $3.4 \mathrm{~kW}$ or a $7 \mathrm{~kW}$ charger. Having the daily driving distances, the necessary State of Charge (SoC) that is required in each day is calculated, assuming linear correlation between the $\mathrm{SoC}$ and the driving range. If the required $\mathrm{SoC}$ for the next day's driving is higher than the current $\mathrm{SoC}$, then the EV has to be charged and its total charging time is derived by,

$$
t_{c h}=\frac{(100-S o C)}{100} \frac{B_{c a p}}{P_{c h}} \text { hours }
$$

The starting time of the charging of each electric vehicle and in each day is selected randomly in the interval 16:00-21:00. A typical resulting charging profile is illustrated in Fig. 5.

\section{CASE STUDIES}

In this section, the operation of the selected LVDG that has been described in Section II is investigated under numerous scenarios, using MATLAB/Simulink. The scenarios include its current condition under seasonal loading, as well as future operational scenarios in which different penetration levels of PVs and EVs are considered.

\section{A. Current Condition}

The operation of the LVDG is simulated for a duration of two weeks during the summer. By comparing the energy drawn from the MV/LV transformer with the energy generation by the installed PVs, the current penetration level of PVs in the energy mix during the summer is calculated at 5.7\%. In Fig. 6, the loading of the overhead distribution line connecting nodes 5 and 9 is illustrated. It can be seen from this figure that the loading conditions in this distribution line are highly asymmetric with phases $a$ and $b$ having similar loading, while
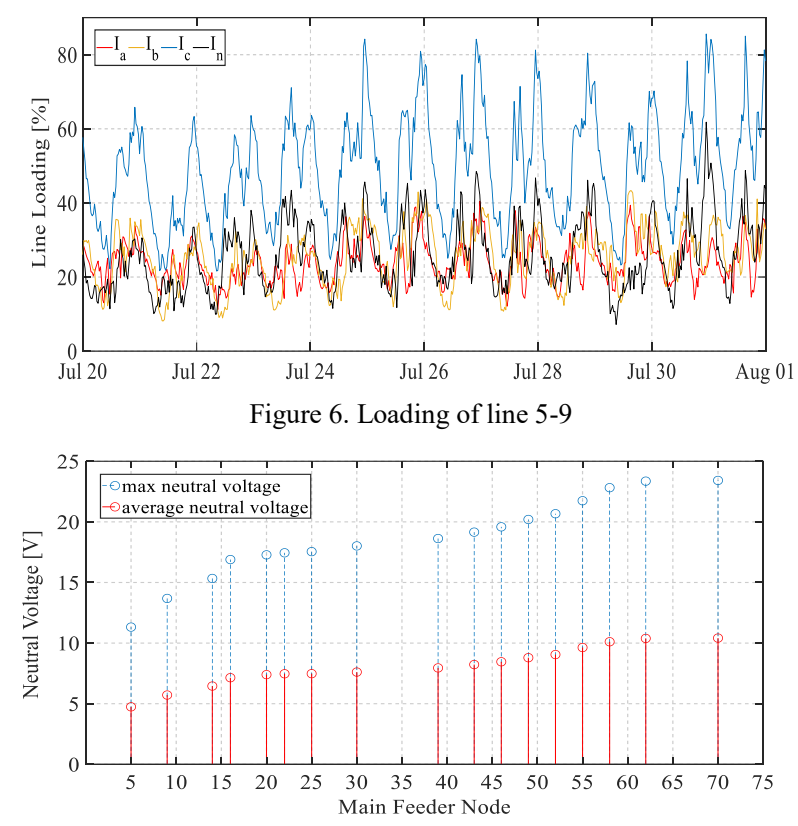

Figure 7. Voltage of the neutral conductor at main feeder nodes

phase $c$ is operating at a significantly higher load. Moreover, it can be concluded that the overhead lines connecting the main nodes of the LVDG near the transformer are close to being overloaded as in some instances the loading of the phase $c$ conductor exceeds $80 \%$ of its capacity. Additionally, the neutral conductor is carrying a significant portion of the total load current (zero sequence current) due to the majority of singlephase consumers in the LVDG (and the asymmetric loading conditions). This current flow in the neutral conductor creates a significant voltage drop across it throughout the whole system, as is evident in Fig. 7. This figure illustrates the average and peak neutral voltage of the main feeder nodes during the simulated period.

According to the transmission/distribution regulations in Cyprus, the phase-to-neutral voltage should be $230 \mathrm{~V} \pm 10 \%$. However, due to the highly asymmetric loading conditions causing a non-negligible neutral to ground voltage at each node, the phase-to-neutral voltage can exceed these limits even if the phase-to-ground voltage is well within the admissible interval [11]. This is illustrated in Fig. 8, which shows the phase-toground, the phase-to-neutral and the neutral-to-ground voltage of a main feeder node. Due to vector summation, if the phase difference between the phase-to-ground voltage and neutral-toground voltage is $\leq 90^{\circ}$, then the phase-to-neutral voltage is less than the phase-to-ground voltage. If the phase difference between the phase-to-ground voltage and neutral-to-ground voltage is $\geq 90^{\circ}$, then the phase-to-neutral voltage is greater than the phase-to-ground voltage. For this reason, $\left|V_{a n}\right|$ and $\left|V_{b n}\right|$ phase-to-neutral voltages are mainly greater than the $\left|V_{a g}\right|$ and $\left|V_{b g}\right|$ phase-to-ground voltages, while $\left|V_{c n}\right|$ is less than $\left|V_{c g}\right|$. In order to determine how severe the possible violation of the admissible limits is in each of the scenarios, the below metric is introduced,

$$
V^{+}=\sum_{i=1}^{N_{V}} \sum_{j_{i}=1}^{n_{i}} \frac{1}{3600} \int_{t_{1}^{j_{i}}}^{t_{2}^{j_{i}}}\left(\left|V_{i}\right|-V_{\text {max }}\right) d t \quad[V h]
$$



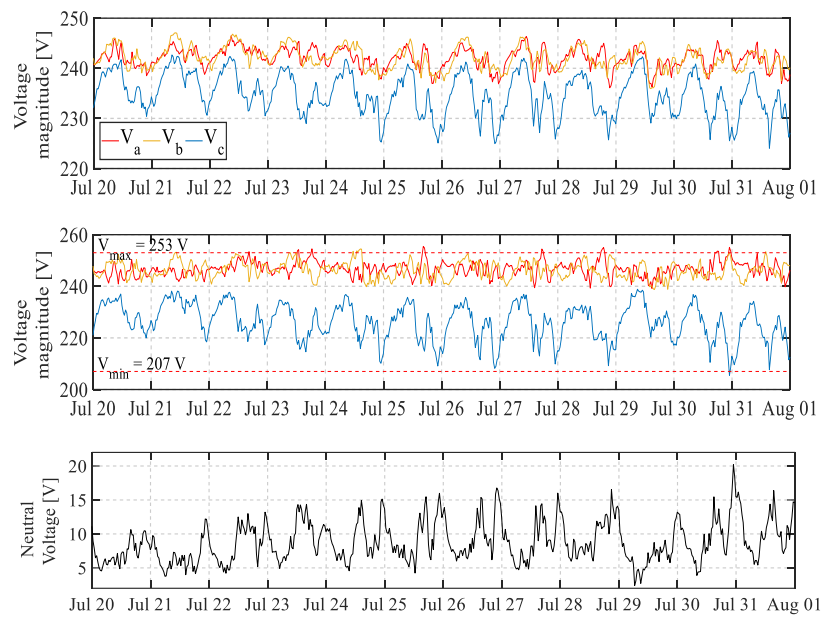

Figure 8. Top: phase-to-ground voltage, middle: phase-to-neutral voltage, bottom: neutral-to-ground voltage

where the index $i$ corresponds to the $i^{\text {th }}$ phase-to-neutral voltage, index $j_{i}$ corresponds to the $j^{\text {th }}$ interval that the $i^{\text {th }}$ phaseto-neutral voltage exceeds the maximum admissible limit $V_{\max }$, and $t_{1}^{j_{i}}, t_{2}^{j_{i}}$ define the start and the end of this interval. The units of this metric are Volthour and a similar metric $V^{-}$can be defined for the violation of the lower limit $V_{\min }$. Using the results from this scenario it is found that currently, during the summer period the metrics $V^{+}$and $V^{-}$for the voltage limit violation are $151.58 \mathrm{Vh}$ and $-257.08 \mathrm{Vh}$ respectively. By dividing these metrics with the overall simulation time (336 hours), the average violation of the admissible limits is found to be $+0.45 \mathrm{~V}$ and $-0.76 \mathrm{~V}$. This is equivalent to having all phase-to-neutral voltages in the feeder within the admissible limits with one voltage however constantly at $253.45 \mathrm{~V}$ (determined as $V_{\max }+0.45$ volt) and one at $206.24 \mathrm{~V}$ (determined as $V_{\min }-0.76$ volt). Hence, these metrics can be used to determine the severity of the admissible limits violation in each of the simulated operating scenarios. A summary of the results under summer and winter seasonal loading is provided in Tables II and III. Due to the lower generation from the PVs during winter under the examined period $(0.74 \mathrm{MWh})$, their penetration during winter is typically $4.7 \%$ in terms of energy. As before, the most loaded distribution line is the line connecting nodes 5 and 9 which reaches $60.7 \%$ of its capacity (in one phase). During this period, there are no instances of a phase-to-neutral voltage violating the $V_{\min }$ limit and therefore $V^{-}=0 \mathrm{Vh}$. The $V^{+}$is equal to $173.62 \mathrm{Vh}$ which corresponds to an average voltage violation of $+0.52 \mathrm{~V}$.

\section{B. Future Operational Scenarios}

In this section, different penetration levels of PVs and a different number of EVs are considered. These scenarios will provide important insights as to how this LVDG will operate in the near future with the introduction of EVs due to the electrification of the transportation sector as well as with the increasing share of the solar energy in the energy mix. Each scenario is examined with a summer and winter seasonal loading and the summary of the simulation results are presented in Tables II-III, while Table IV contains the nodes that the new $2.5 \mathrm{~kW}$ PV systems and EV charging facilities are located in each of the scenarios. In Tables II-III, the Losses column refers to the total energy that is consumed by the distribution

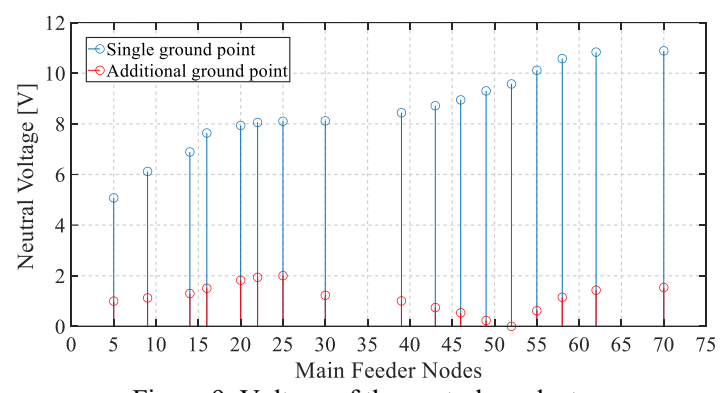

Figure 9. Voltage of the neutral conductor

lines/cables and the transformer during the simulated time. The $P V$ energy column shows the total energy produced by the PVs in the system during the simulated period. The Reverse power column shows how much energy is exported from the LVDG into the medium voltage grid and its corresponding average power (even if this metric is zero, there can still be reverse power inside the LVDG, but it is not enough to reach the transformer). The Max loading shows the peak loading that a line reaches (in this occasion it was always line 5-9) during the simulations. The last two columns contain the average voltage violation metrics $V^{+}$and $V^{-}$regarding the violation of $V_{\max }$ and $V_{\text {min }}$ limits respectively.

From Tables II-III, it can be seen that by increasing the penetration level of PVs alone, $V^{+}$increases significantly due to the reverse power inside the LVDG which raises the voltage. With a significant number of EVs this effect is partially compensated since the increased load reduces the reverse power. However, this also increases the neutral voltage inside the LVDG which has a negative effect on $V^{-}$. These effects are greatly influenced by the location of both the PV systems and the EVs inside the LVDG. If they are concentrated near the end of the LVDG and not spread out, then these effects will be stronger. As it was mentioned, these violations of the voltage limits are due to the significant voltage drop across the neutral conductor. Therefore, by grounding the neutral conductor at an additional point besides at the MV/LV transformer, the voltage profile of the whole feeder should improve in a significant degree. In Table $\mathrm{V}$, the simulation results of the same operating scenario are illustrated in which however, in the second simulation, denoted as $\mathrm{N}^{+}$, the neutral conductor is grounded not only at the $\mathrm{MV} / \mathrm{LV}$ transformer, but also at node 52 (change from $100 \mathrm{~mm}^{2}$ to $50 \mathrm{~mm}^{2} \mathrm{OHL}$ ). From these results it can be seen that the additional grounding point for the neutral conductor does not have any significant effect on the loading of the LVDG, however it reduces significantly the voltage limit violations (by $84 \%$ and $83 \%$ improvement in $V^{+}$and $V^{-}$ respectively). By providing an additional grounding point for the neutral conductor inside the LVDG, the voltage drop across it is reduced considerably, as is evident in Fig. 9. Therefore, the phase-to-neutral voltages are closer to the phase-to-ground voltages, which most of the time satisfy the operational limits.

Furthermore, from the Losses column it can be seen that by increasing the PV penetration from 5\% to $15 \%$, a reduction of losses is achieved. As more power is generated closer to the consumption, the losses from the distribution lines are lower. Moreover, in the case of $\mathrm{N}^{+}$, the extra grounding of the neutral conductor reduces significantly its current profile which decreases its losses. 


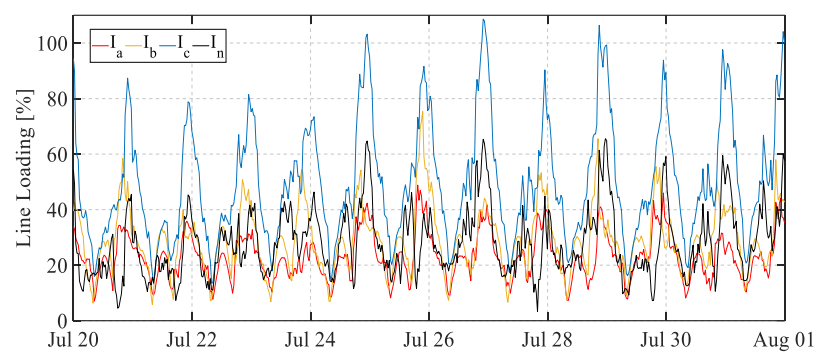

Figure 10. Loading of line 5-9 (summer, 35\% PVs and 10 EVs)

TABLE II

SUMMARY OF RESUlTS, SUMMER PERIOD

\begin{tabular}{|c|c|c|c|c|c|c|}
\hline \multirow{3}{*}{ Scenario } & \multicolumn{6}{|c|}{ Summer } \\
\hline & \multirow{2}{*}{$\begin{array}{c}\text { Losses } \\
(\mathrm{kWh})\end{array}$} & \multirow{2}{*}{$\begin{array}{l}\text { PV energy } \\
(\mathrm{MWh})\end{array}$} & \multirow{2}{*}{$\begin{array}{l}\text { Reverse } \\
\text { power }\end{array}$} & \multirow{2}{*}{$\begin{array}{c}\text { Max } \\
\text { loading } \\
(\%)\end{array}$} & \multicolumn{2}{|c|}{$\begin{array}{c}\text { Violation of } \\
\text { voltage limits }\end{array}$} \\
\hline & & & & & $V^{+}(\mathrm{V})$ & $V^{-}(\mathrm{V})$ \\
\hline $\begin{array}{c}\text { Current } \\
\text { condition }\end{array}$ & 1335 & 1.39 & - & 85 & +0.45 & -0.76 \\
\hline $15 \% \mathrm{PV}$ & 1236 & 3.65 & - & 87 & +1.76 & -1.11 \\
\hline $\begin{array}{c}25 \% \text { PV \& } \\
3 \text { EVs }\end{array}$ & 1325 & 5.95 & $\begin{array}{l}23.8 \mathrm{kWh}, \\
70.8 \mathrm{~W}\end{array}$ & 98 & +9.14 & -4.79 \\
\hline $\begin{array}{c}35 \% \text { PV \& } \\
10 \text { EVs }\end{array}$ & 1499 & 8.31 & $\begin{array}{l}600 \mathrm{kWh}, \\
1.79 \mathrm{~kW}\end{array}$ & 109 & +2.79 & -8.4 \\
\hline
\end{tabular}

TABLE III

SuMMARY OF RESUlTS, WinTER PERIOD

\begin{tabular}{|c|c|c|c|c|c|c|}
\hline \multirow{3}{*}{ Scenario } & \multicolumn{6}{|c|}{ Winter } \\
\hline & \multirow{2}{*}{$\begin{array}{l}\text { Losses } \\
(\mathrm{kWh})\end{array}$} & \multirow{2}{*}{$\begin{array}{l}\text { PV energy } \\
\text { (MWh) }\end{array}$} & \multirow{2}{*}{$\begin{array}{l}\text { Reverse } \\
\text { power }\end{array}$} & \multirow{2}{*}{$\begin{array}{l}\text { Max } \\
\text { loading } \\
(\%)\end{array}$} & \multicolumn{2}{|c|}{$\begin{array}{c}\text { Violation of } \\
\text { voltage limits }\end{array}$} \\
\hline & & & & & $V^{+}(\mathrm{V})$ & $V^{-}(\mathrm{V})$ \\
\hline $\begin{array}{c}\text { Current } \\
\text { condition }\end{array}$ & 732 & 0.74 & - & 60 & +0.52 & - \\
\hline $15 \% \mathrm{PV}$ & 670 & 2.03 & - & 57 & +0.77 & - \\
\hline $\begin{array}{c}25 \% \text { PV \& } \\
3 \text { EVs }\end{array}$ & 744 & 3.19 & $\begin{array}{l}202 \mathrm{kWh} \text {, } \\
601 \mathrm{~W}\end{array}$ & 69 & +4.66 & - \\
\hline $\begin{array}{c}35 \% \text { PV \& } \\
10 \text { EVs }\end{array}$ & 872 & 4.54 & $\begin{array}{c}921 \mathrm{kWh} \text {, } \\
2.74 \mathrm{~kW}\end{array}$ & 86 & +1.42 & -0.07 \\
\hline
\end{tabular}

TABLE IV

LOCATION OF ADDITIONAL PVS AND EVS IN THE SimULATION

\begin{tabular}{c|c|c}
\hline \hline Scenario & Nodes with additional PVs & Nodes with additional EVs \\
\hline \hline $15 \%$ PV & $\{27,36,48,56,57,71,73\}$ & - \\
\hline $25 \%$ PV \& 3 EVs & $\{12,15,23,29,34,50,68\}$ & $\{17,31,48\}$ \\
\hline $35 \%$ PV \& 10 EVs & $\{4,11,37,54,60,61,64\}$ & $\{7,24,27,34,40,57,69\}$ \\
\hline \hline
\end{tabular}

TABLE V

ADDITIONAL GROUNDING POINT FOR THE NEUTRAL CONDUCTOR

\begin{tabular}{ccccccc}
\multicolumn{2}{c}{ ADDITIONAL GROUNDING POINT FOR THE NEUTRAL CONDUCTOR } \\
\hline \hline Scenario & $\begin{array}{c}\text { Losses } \\
(\mathrm{kWh})\end{array}$ & $\begin{array}{c}\text { PV } \\
\text { energy } \\
(\mathrm{MWh})\end{array}$ & $\begin{array}{c}\text { Reverse } \\
\text { power }\end{array}$ & $\begin{array}{c}\text { Max } \\
\text { loading } \\
(\%)\end{array}$ & \multicolumn{2}{c}{$\begin{array}{c}\text { Violation of } \\
\text { voltage limits }\end{array}$} \\
$V^{+}(\mathrm{V})$ & $V^{-}(\mathrm{V})$ \\
\hline \hline $25 \%$ PV \& 3 EVs & 1325 & 5.95 & $\begin{array}{c}23.8 \mathrm{kWh}, \\
70.8 \mathrm{~W}\end{array}$ & 98 & $+\mathbf{9 . 1 4}$ & -4.79 \\
\hline $\begin{array}{c}25 \% \text { PV \& 3 EVs, } \\
\mathrm{N}^{+}\end{array}$ & 1233 & 5.95 & $\begin{array}{c}23.8 \mathrm{kWh}, \\
70.8 \mathrm{~W}\end{array}$ & 98 & +1.42 & -0.80 \\
\hline \hline
\end{tabular}

Another important observation from the simulation results is that the increase of EVs inside the LVDG can overload the distribution lines near their beginning. In Fig. 10 the loading of the line 5-9 is illustrated for the scenario with $35 \% \mathrm{PV}$ penetration and $10 \mathrm{EVs}$. Although the loading of phases $a$ and $b$ is below $60 \%$ for most of the time, the conductor of phase $c$ operates constantly at higher loadings which for short time instances it even exceeds $100 \%$ of its capacity. This is due to the asymmetrical loading but also due to the charging power required by the EVs. This shows that even with a moderate number of EVs, the security of the LVDG is at risk. Therefore, to maintain its secure operation with a larger number of EVs, their charging must be accomplished in a smart coordinated scheme and not allowed freely to end users. It must be noted that the charger for each EV in the LVDG was connected with the same configuration as its corresponding house (the same is valid for the inverter of the PVs as well). In the case of a house being supplied by a single phase, if a new three phase connection can be established for the EV charger then this will reduce in some degree the loading asymmetry.

\section{CONCLUSIONS}

This paper investigated the impact of PVs and EVs in an LVDG in Cyprus. The results have shown that even with a moderate penetration of PVs, the admissible voltage limits can be exceeded due to the significant voltage drop across the neutral conductor. However, it was identified that the increased PV penetration can also aid towards the reduction of losses. In an effort to minimize the voltage violations, it was proposed to provide an additional grounding point for the neutral conductor. This simple and low cost solution has as a result a considerable reduction of the voltage limit violations. The results have also revealed highly asymmetrical loading conditions which reduce the utilization of existing capacity and may cause violation of the rating capacity of the LVDG, especially under high penetration of EVs. The studies performed in this paper indicate that there is a need for proper monitoring and control schemes for LVDGs in order to ensure the secure, efficient and reliable operation of the grid.

\section{REFERENCES}

[1] A. Ipakchi and F. Albuyeh, "Grid of the future," IEEE Power and Energy Magazine, vol. 7, no. 2, 2009, pp. 52-62.

[2] N. Aste, F. Groppi and C. Del Pero, "The first installation under the Italian PV rooftop programme: A performance analysis referred to 11 years of operation," in Proc. IEEE ICCEP, Alghero, Italy, 2013.

[3] International Energy Agency (2017). Status of Power System Transformation - Summary for Policy Makers. Available: https://www.iea.org/publications/freepublications/publication/StatusofPower SystemTransformation2017SummaryforPolicyMakers.pdf

[4] L. Mukwekwe, C. Venugopal and I. E. Davidson, "A review of the impacts and mitigation strategies of high PV penetration in low voltage networks," in Proc. IEEE PES-IAS Power Africa, Accra, Ghana, 2017.

[5] C. Zhao, C. Gu, F. Li and M. Dale, "Understanding LV network voltage distribution - UK smart grid demonstration experience," in Proc. IEEE ISGT, Washington, USA, 2015.

[6] D. Waeresch, R. Brandalik, W. Wellssow, J. Jordan, R. Bischler and N. Schneider, "Linear state estimation in low voltage grids based on smart meter data," in Proc. IEEE PowerTech, Eindhoven, Netherlands, 2015.

[7] Y. Hou, J. Magnusson, G. Engdahl and L. Liljestrand, "Impact on voltage rise of PV generation in future swedish urban areas with high PV penetration," in Proc. IEEE Energycon, Dubrovnik, Croatia, 2014.

[8] A. S. Masoum, P. S. Moses, M. A. Masoum and A. Abu-Siada, "Impact of rooftop PV generation on distribution transformer and voltage profile of residential and commercial networks," in Proc. IEEE ISGT, Washington, USA, 2012.

[9] W. H. Kersting, Distribution System Modeling and Analysis, $4^{\text {th }}$ Edition, CRC Press, 2017.

[10] Electricity Authority of Cyprus (2016, Dec.). TEXNIKO

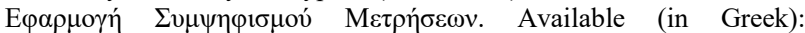
https://www.eac.com.cy/EL/EAC/RenewableEnergySources/Documents

[11] A. Kotsonias, L. Hadjidemetriou, M. Asprou and E. Kyriakides, "Performance investigation of a monitoring scheme for low voltage grids with a single grounded neutral," in Proc. IEEE PowerTech, Milan, Italy, 2019. 